\title{
TO THE EFFECTIVENESS OF COASTAL AND FLOOD PROTECTION STRUCTURES UNDER TERMS OF CHANGING CLIMATE CONDITIONS
}

\author{
Peter Fröhle
}

Consequences resulting from future Climate Change may be one of the most severe threats for people and economies in many countries of the world. Besides the problem of sea level rise, also possible general changes in the frequency and intensity of storms as well as general changes in the average wind field are expected for the future.

With respect to the coastal protection possible future strategies and also possible future measure are analyzed and assessed with the result that technical, morphological, socio-economic and aesthetical aspects play a role.

Keywords: climate change; adaptation methods; flood protection

\section{INTRODUCTION}

Problems related to climate change and the predicted global warming are being discussed worldwide at present. Serious estimations assume that - depending on the selected scenario - a rise of the temperatures of at least $2^{\circ} \mathrm{C}$ during the next 100 years (see Fig. 1) will be unavoidable. Politicians world-wide have agreed in the target to limit future temperature rise to $2^{\circ} \mathrm{C}$. Many states have also decided to make this target to the basis of their climate protection policy and to implement climate protection measures accordingly (WBGU 2009). Despite the fact that a $2^{\circ}$ limit is the target for many states, climate change researchers assume that the future rise of the global temperatures will be (significantly) higher.

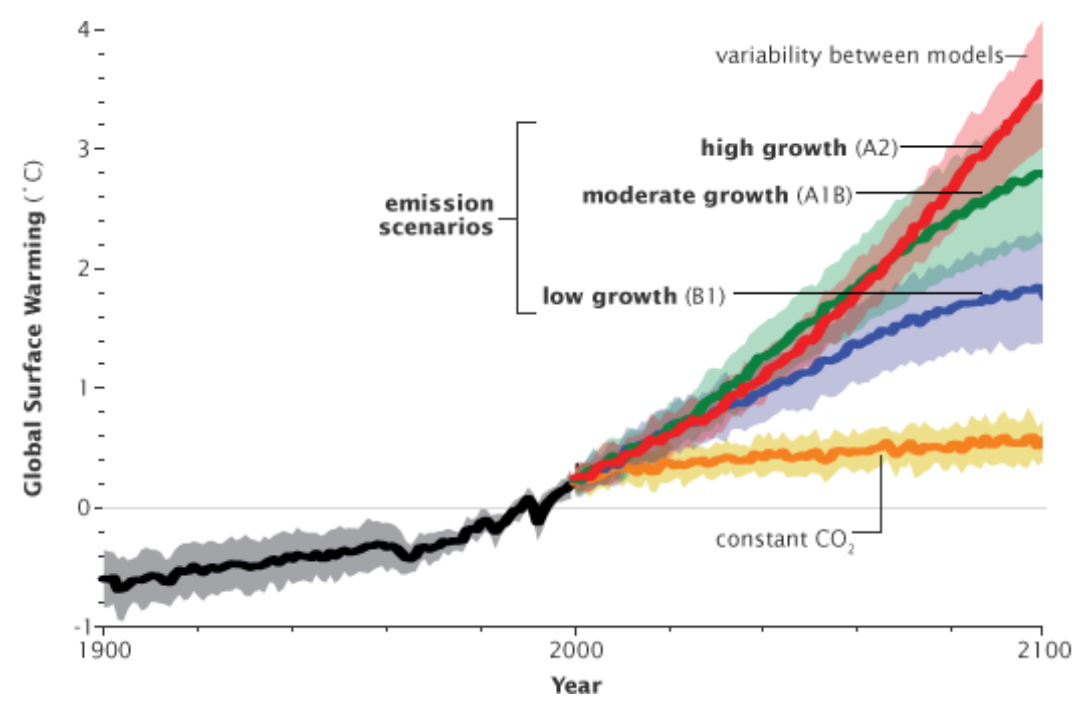

Figure 1. Projections of global warming (source: NASA: Earth Observatory, 2010) (http://earthobservatory.nasa.gov/Features/GlobalWarming/page5.php).

Consequences resulting from future climate change may be one of the most severe threats for people and economies in many countries of the world. At present, IPCC (2007) is estimating a worldwide average sea level rise of less than $1.0 \mathrm{~m}$ within the $21 \mathrm{st}$ century. Other sources (e.g. RAHMSTORF \& SCHELLNHUBER, 2007) which are taking into account possible melting of the two main continental ice covers (Greenland and Antarctica), estimate significantly higher values especially over long periods.

Small islands and low lying coastal regions are the most vulnerable areas against accelerated sea level rise. The main questions for these areas are, whether the natural morphological development of these low lying areas is fast enough to adapt to the sea level rise, or, whether coastal protection measures can protect the areas against flooding in the long-run.

\footnotetext{
${ }^{1}$ Institute of River and Coastal Engineering, Hamburg University of Technology (TUHH), Denickestr. 22, D-21073 Hamburg, Germany
} 
With rising water levels and changed hydrodynamic loads on the coast the question arises whether the actual coastal flood defense and protection constructions and the corresponding concepts are effective on medium term (decadal scale) and long-term (end of 21st century) engineering time scales. Within the context of the changed climatic conditions and the planning periods in coastal engineering, it is necessary to develop sustainable long-term strategies for coastal flood defense and protection based on the actual situation.

\section{CLIMATE CHANGE AND HYDRODYNAMIC CONDITIONS}

\section{Water Levels}

One of the most important expected effects resulting from the increase of the temperatures is the world-wide accelerated increase of the local water levels in the seas and oceans. With respect to the protection of coastal areas, the changes of the sea level are related to

i) a rising of the mean sea level and / or

ii) possible increase of storm induced extreme water levels (wind set-up).

\section{Mean Sea Level}

An increase of the mean sea level is monitored since more than a century (Fig. 2) for many water level gauges around the world. The long term rates of this world-wide sea level rise are in the range between 1 and $2 \mathrm{~mm} / \mathrm{a}$. Actual trends are monitored with the use of altimeter data from Satellites by NOAA. The measured rates of the sea level rise are calculated to $2.8 \pm 0.4 \mathrm{~mm} /$ year for the last 20 years, which is higher than the average rate of the past centuries Fig. 3.

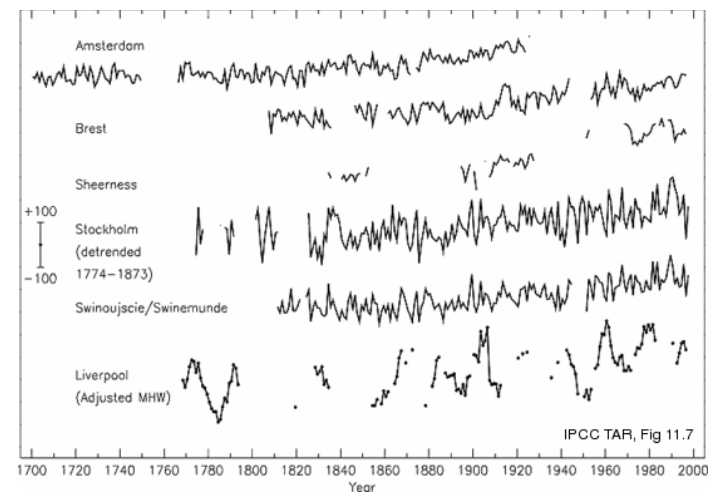

Figure 2. Long term sea level changes (IPCC Third Assessment Report, Fig. 11.7, 2007).

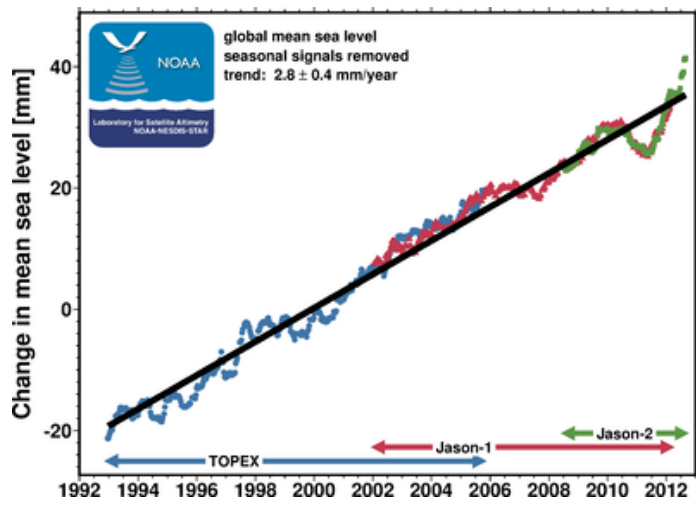

Figure 3. Time series of global mean sea level (annual signals removed) measured by altimeter Satellite (NOAA Laboratory for Satellite Altimetry, Source http://ibis.grdl.noaa.gov/SAT/SeaLevelRise/

Basically, the absolute changes of the mean sea level are divided into eustatic and isostatic changes, where isostatic changes result from the loading / unloading of the earth crust caused by the last ice age and/or by seismic changes of the earth's crust. The eustatic changes result mainly from the temperature effects of climate change and are therefore directly related to global warming. The relative changes, which are in the last consequence decisive for coastal protection, result from the addition of the local isostatic and eustatic changes.

Analyses on the global scale indicate an accelerated sea level rise for the future. Global projections are in the order of 0.2 to $0.8 \mathrm{~m}$ for the time period $1990-2100$ (IPCC, 2007), newer investigations result in significantly higher values (e.g., Vermeer and Rahmstorf, 2009), see Fig. 4. 

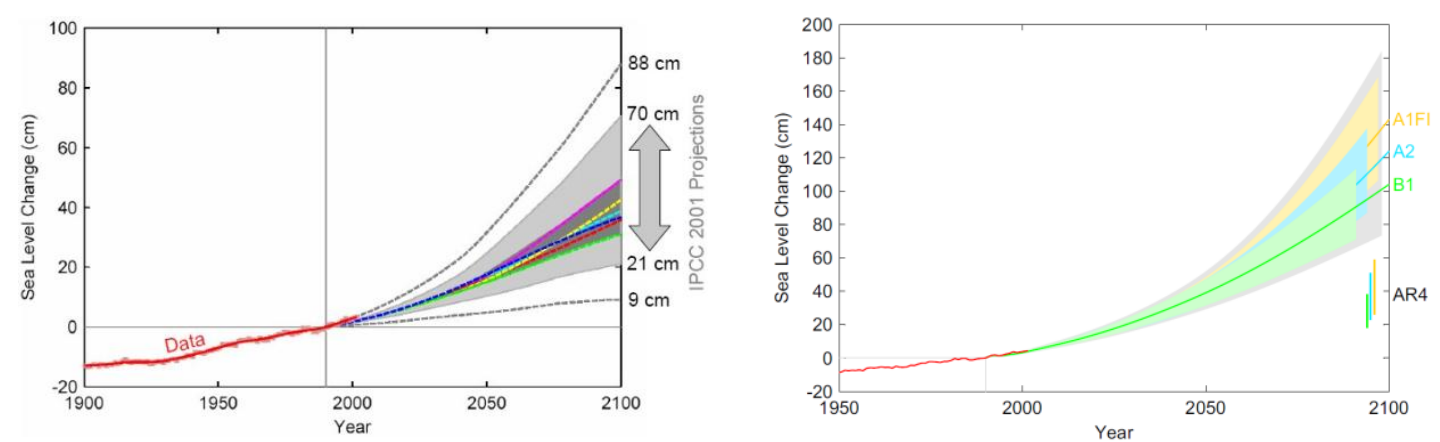

Figure 4 .. Projections of the future sea level rise by IPCC $\left(4^{\text {th }}\right.$ assessment report, left graph) and Vermeer \& Rahmstorf (2009, right graph)

\section{Storm Surge Water Levels}

Besides the effects of increased mean sea level, the increase of storm surge water level is of extreme importance for applications in Coastal Protection. Despite the fact that many people assume an increase in intensity and frequency of storm events and correspondingly an increase in the intensity and frequency of coastal flooding for the future, a direct scientific evidence for an increase of the storm intensity and frequency is at present not available (e.g. von Storch et al., 2009). The ranges of possible effects of climate change on the storms are mainly depending on the location and cannot be generalized for world-wide applications. Hence, in the following, an example of possible changes of extreme events in the German Baltic will be given.

Fig. 5 shows the development of storm surge water levels for the gauge Warnemünde at the Baltic Sea. The local linear trend of the storm surge water levels in the period 1855 to 2009 is higher $(1.96 \mathrm{~mm} / \mathrm{a})$ than the linear trend of the average water levels which has been analyzed to $1.23 \mathrm{~mm} / \mathrm{a}$ for the gauge Warnemünde. This result -which is valid for many gauges around the German Baltic Seasupports the hypothesis that the storm intensity will increase or is already increasing (see also following section). Nevertheless, the highest water levels at the gauge Warnemünde have been observed at the end of the 19th century and at the beginning of the 20th century and the maximum water levels in the last 50 years are significantly lower than these extreme high water levels. Besides this, the linear trend of the storm surge levels in the period from 1900 to 2009 has nearly exactly the same value $(1.20 \mathrm{~mm} / \mathrm{a})$ as the linear trend of the average water levels. This may indicate that storm surge water levels in the German part of the Baltic Sea are increasing for "average" storms, only, and are not increasing for extreme storm events.

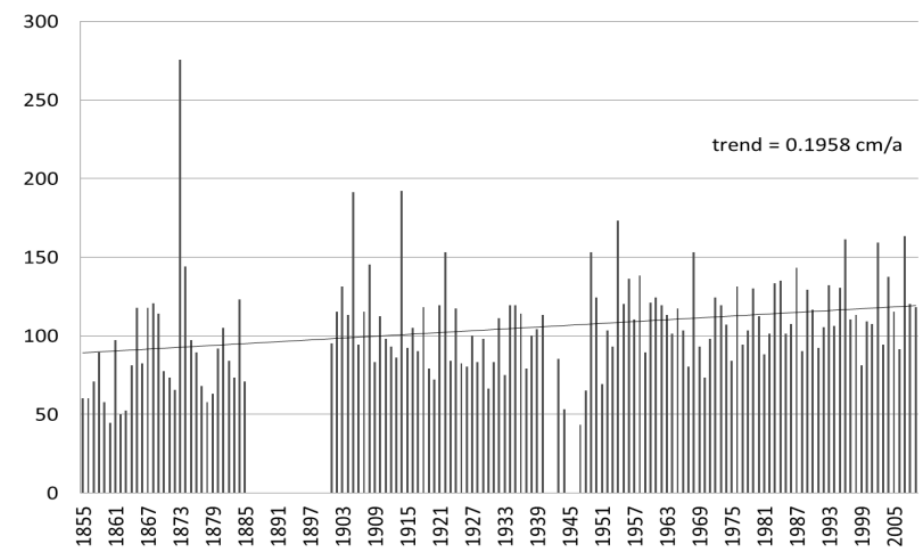

Figure 5. Development of yearly maximum water levels in Warnemünde period 1855 - 2009, Baltic Sea (Data Source WSA Stralsund).

According to the information distributed by the Northern German Climate Bureau (Norddeutsches Klimabüro, www.norddeutscher-klimaatlas.de) it is still unclear, whether or not the intensity of storms in average per year will in-crease up to the end of the 21 st century (period 2071 - 2100) compared to the period between 1961 to 1990 (Fig. 6a). There are some indications that in the winter period the 
storm intensity will increase even if the statistical significance of the simulation results is not very high at present (Fig. 6b). The values given in the BACC-report (2008) also indicate an increase of the storm intensity and resulting on the storm surge water levels, even if the order of magnitude of the water levels for a storm flood event with a return period of 1 per 100 years seem, especially for the German Baltic Sea coast, significantly too low.

From these brief analyses it is concluded that, for the German Baltic Sea, the increase of the storm surge water levels will be at least in accordance with the increase of the mean sea level.
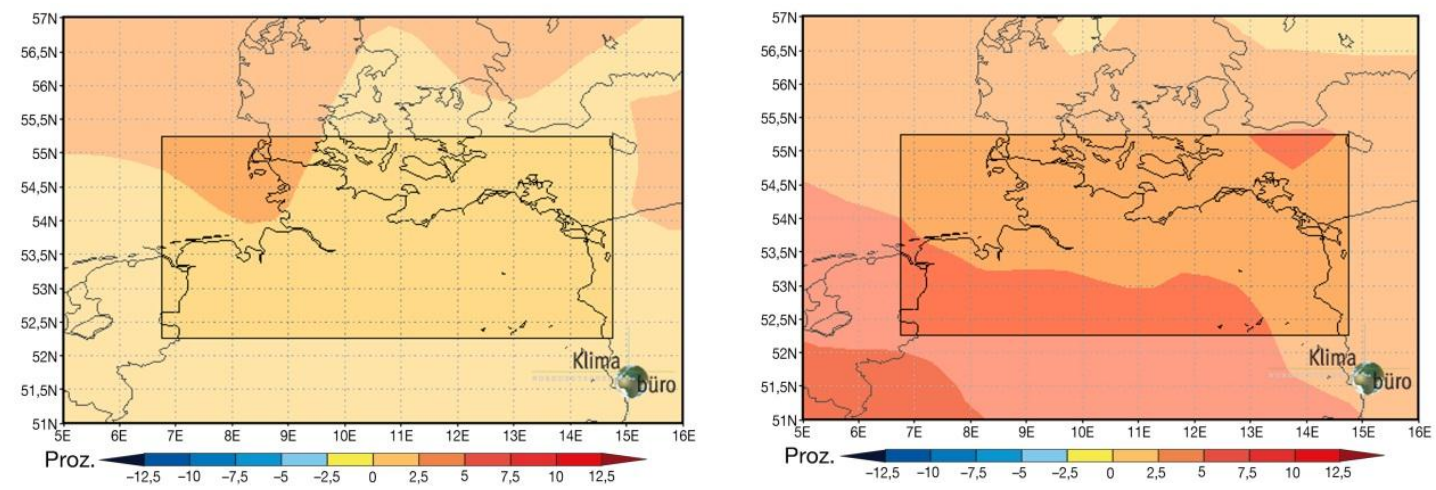

Figure 6. Changes of Storm Intensity in the German Baltic Sea area, average scenario a) Yearly Average 2070-2100 comp. 1960-1990, b) winter season 2070-2100 comp. 1960-1990. (Source: www.norddeutscherklimaatlas.de, Meinke \& Gerstner, 2009).

\section{Waves and Sea State}

Average Conditions

The local average sea state (wave conditions) is generated by the wind-field within the fetch area. This means that changes in the wind-field (velocity and direction) are affecting the wave conditions directly. According to the model results of NASA (data.giss.nasa.gov, Fig. 7) the changes of the wind speed are very uneven distributed over the globe. In general, the changes are comparatively small and the simulated changes are complex. There is a clear increase of the average wind velocities in the Southern Oceans (around $60^{\circ} \mathrm{S}$ ). There is also an increase of the average wind velocities near the equator which may be associated with increases in convective activity. Decreases of the wind velocities are calculated around $30^{\circ} \mathrm{N}$ and -not so significant- around $30^{\circ} \mathrm{S}$. Changes over the big land masses are in general very small.

Mori et al. (2009) have investigated the changes of the ocean waves based on climate change scenarios (Fig. 8). The general pattern of the wave height changes fits very well with the general pattern of the changes of the average wind velocities. Hence, it can be stated that an increase of wave heights must be expected in the above mentioned areas with increased wind speed. It can also be seen from Fig. 8 that the changes of the wave heights caused by changes of the wind speed near the coast are small compared to the changes on the open ocean.
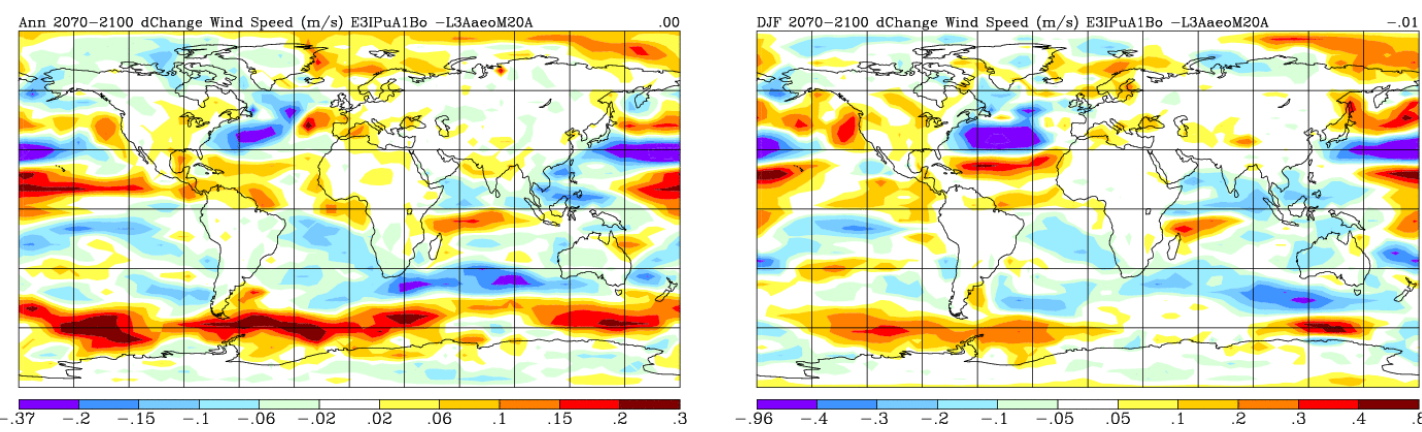

Figure 7. Changes of average wind velocity $(\mathrm{m} / \mathrm{s})$ 2070-2100 compared to 1970-2000, scenario A1B, a) yearly average, b) north winter season,

(Source: NASA http://data.giss.nasa.gov/modelE/transient/Rc_ij.4.03.html)First 3 normalized frequencies versus release location for clamped simply supported beam with internal slide release. 


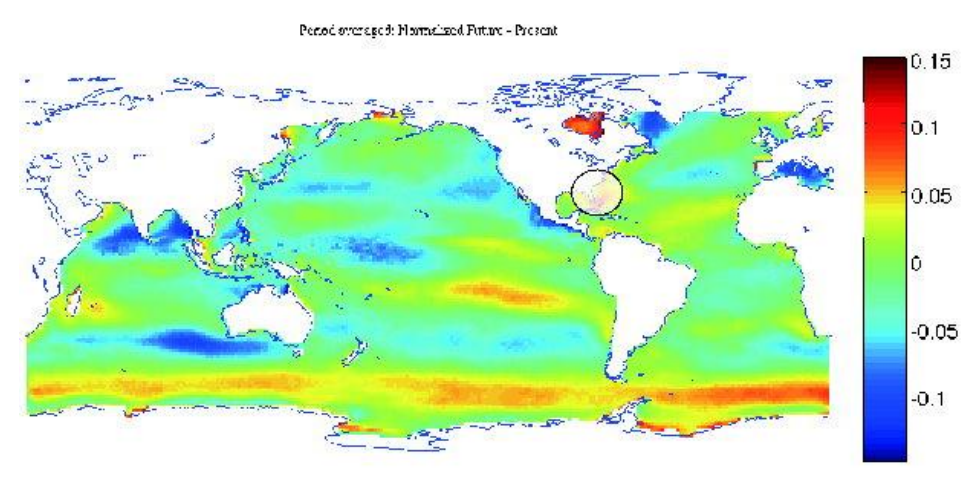

Figure 8. Changes of average wave heights, ratio of averaged wave height change from the present (19782004) to future (2075-2099) climate conditions, (Mori et al., 2009).

Dreier, et al. (2012) investigated possible future changes in the local wave climate of the Baltic Sea on the basis of wind-wave correlations and wind information from climate change consortial runs using the CLM regional model in combination with the ECHAM5 global climate model. These analyses show a small increase of probabilities for higher wave and a small decrease of probabilities for lower wave heights. Hence, the model results indicate a small increase of the overall wave energy input for the future for all selected climate change scenarios, respectively. However, the projected changes are all comparatively small and well below $1.5 \%$.

Possible changes in the wind-directions over the Baltic Sea are as relevant as changes of the wind speed and corresponding wave height changes, especially, in connection with waves and the effects of waves on coasts. Information on possible changes of wind directions and also wave directions are not available from the literature at present. If the wind-directions are changing in future, the wave directions and storm surge heights will follow these changes correspondingly. Calculations based on possible future climate change scenarios indicate (Dreier, et al. 2012) a change in the local wind directions at the German Baltic Sea Coast (Fig. 10). Westerly wave directions may increase by up to $3.5 \%$, whereas easterly and north easterly directions may decrease by one to two percent.

It is questionable, whether or not such minor changes as predicted by Mori et al. or Dreier et al. are statistically significant. In general it can be stated that only minor changes of the average wave conditions have to be expected in the future.

Extreme Events

Detailed analyses of changes in extreme wave conditions are not available at present. Analyses of Mori et al. indicate that possible changes of extreme events are strongly depending on local effect and have therefore to be analyzed carefully for specific areas. According to the BACC group (2008), it could be possible that extreme wave conditions increase at least in a statistical sense. The BACC group states an increase of the $90 \%$ percentile of the wave height of up to $0.5 \mathrm{~m}$ for the Baltic Sea. Schlamkow et al. (2012) showed (Fig.. 9)) that no clear tendency towards a general increase or decrease of extreme wave heights can be concluded from their analyses and that the results are spreading widely depending on different scenario runs and the projection periods. The results for increase / decrease of extreme wave heights spread between $\pm 15 \%$ for different scenario runs, which means that an increase of extreme wave conditions can not be excluded for the future.

\section{CONSEQUENCES FOR COASTAL FLOOD AND EROSION PROTECTION}

Coastal flood defense and coastal protection systems are supposed to have a life and operating time of approx. 50 to 100 years. Hence, also long-term gradual changes of the loads are of importance. Secular changes and long-term trends of the mean sea level even in a range between $0.1 \mathrm{~m} / 100$ years and $0.3 \mathrm{~m} / 100$ years have been taken into account for the design of coast and flood protection structures. Along the German North Sea coast, during the last years, a climate safety margin of $0.5 \mathrm{~m} / 100$ years is taken as a consequence of higher SLR projections. Within the context of the accelerated sea level rise caused by the global climate change the question arises, which consequences have to be drawn for the methodology and design of future coastal protection concepts and constructions. 

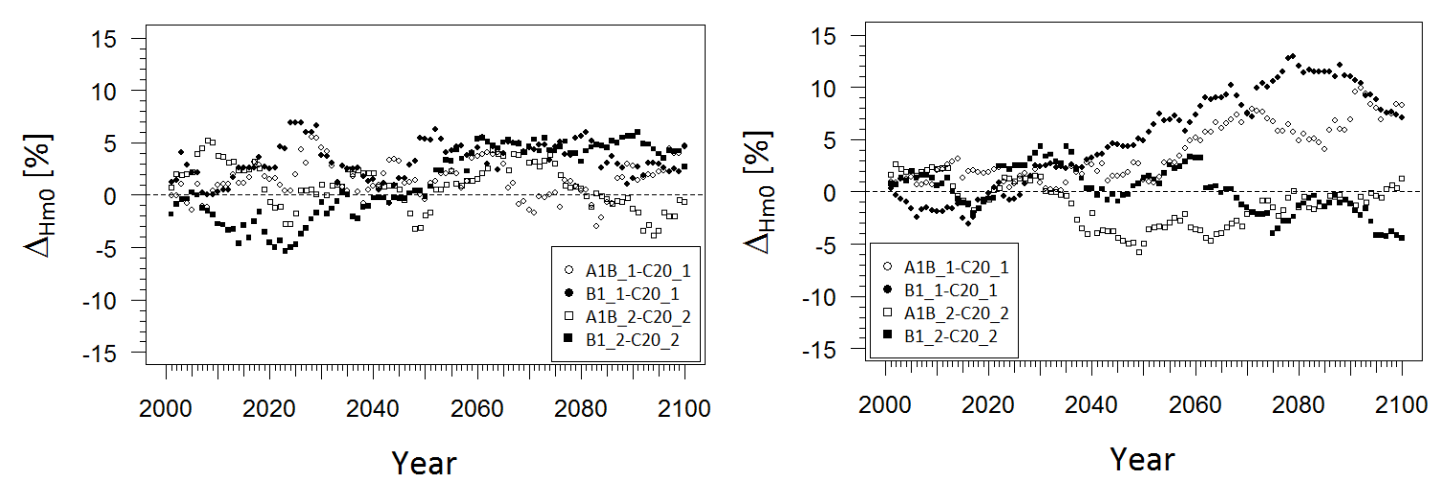

Figure 9. Change of extreme wave heights over time periods of 40 years for different model runs of the climate change scenarios A1B and B1 compared to

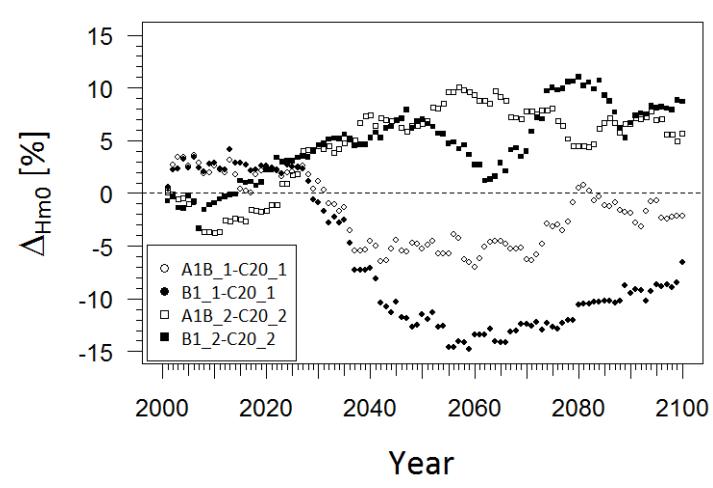
the control period (1961-2000), near Warnemünde (top left), Travemünde (top right) and Westermarkelsdorf (bottom left), (from Schlamkow et al. 2012).

\section{Flood defense}

In the context of this paper, wave run-up and overtopping at dykes and revetments will be considered, exemplarily. Here, the wave conditions at the toe of the construction are the critical values used for the design. Wave conditions at the toe of a dyke or a revetment are often depth limited. Hence, not the deep water conditions but the shallow water wave conditions are the applicable for the design of the constructions. If we assume that the morphology of the coast in front of a dyke or a revetment can follow the sea level rise, solely possible changes of the storm surge water levels are the reason for higher waves at a construction and have to be taken into consideration. If the morphology cannot completely follow the sea level rise, consequently, the wave conditions at the toe of a construction will change i.e. increased wave heights and most probably also longer wave periods will occur at the foot of these constructions.

Fig. 10 shows exemplarily and generalized the changes in the wave overtopping rates at a sloped construction for changed water levels at the toe of a construction. The results indicate that even without taking into consideration higher wind speeds and / or higher additional flood water levels the height of the constructions has to be increased to ensure comparable safety for the construction and, consequently, in the protected areas. A dyke is going to be unsafe from a sea level rise of approx. 0.3 to $0.5 \mathrm{~m}$ onwards, since overtopping rates are coming into a range which endangers the construction. 


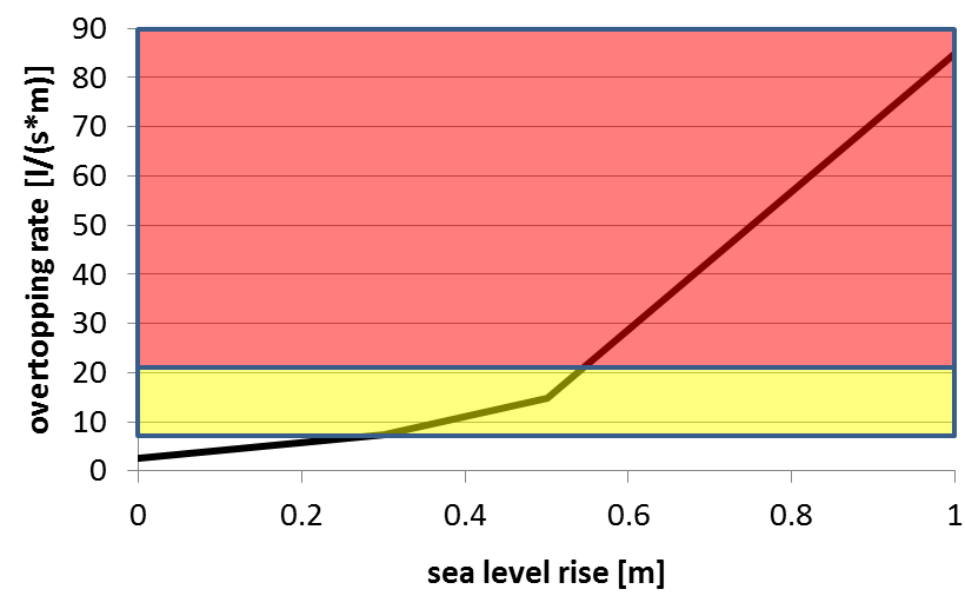

Figure 10. Erosion rate of a selected coastal profile on a sea level rise of $1 \mathrm{~m}$ (left, Fröhle 2009) and generalized coastal retreat for an increase of the mean sea level (right graph).

Sediment transport and protection of sandy coasts

For an assessment of the morphological development of a cross-shore coastal profile it is often assumed that a so called dynamic equilibrium profile, which is depending on the incoming waves, is developing at a coastal stretch. Based on this equilibrium profile a possible morphological reaction of the coast to hydrological changes has been calculated. For the calculation of the reaction of a coast to a changed mean sea level, it was assumed that the cross-shore profile of a coast is constant (dynamic equilibrium) and only based on the relative mean water level and that the necessary amount of sediment for the development of the profile is coming from the cross-shore sediment transport. Furthermore, it was assumed that the long-shore components of the sediment transport can be neglected. Under these assumptions the reaction of the coast was calculated by balancing the eroding and accumulating areas of the cross shore profile. For a freely chosen example cross-section the coast will retreat in an order of magnitude of approx. $100 \mathrm{~m}$ for a sea level rise of $1 \mathrm{~m}$ (Fig. 11). Other, comparative calculations with different assumed amounts of sea level rise from $\mathrm{SLR}=0 \mathrm{~m}$ to $\mathrm{SLR}=1.0 \mathrm{~m}$ showed that for the selected case the retreat of the coast is approx. 100-times the amount of the sea level rise. This retreat is high, compared to the actual rates of coastal retreat which is presently in average around $10 \mathrm{~m}$ to $30 \mathrm{~m}$ per century at the German part of the Baltic Sea.
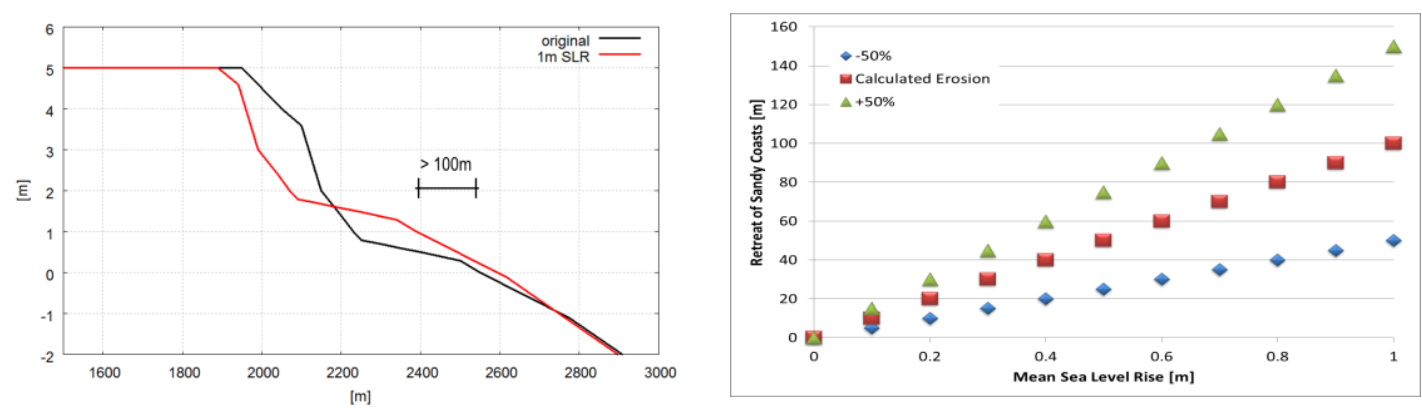

Figure 11. Erosion rate of a selected coastal profile on a sea level rise of $1 \mathrm{~m}$ (left, Fröhle 2009) and generalized coastal retreat for an increase of the mean sea level (right graph).

The amount of the long-shore sediment transport is depending mainly on the incoming wave energy. The direction of the long-shore sediment transport is depending on the direction of the incoming wave energy. Comparison calculations for the Island of Sylt (Witte et al. 2002) showed that, as long as the morphological changes of the coast are accepted and taken into consideration (see also cross-shore transport) and a moderate climate change is assumed, the amount of long-shore-transported sediments is practically the same and that merely the directions of the sediment transport is changing. These changes are strongly depending on the actual location and have to be taken into consideration for practical applications, respectively. Newer analyses (University of Rostock, 2011 or Dreier et al. 2012) show the significant influence of the changes of the wind directions on the long-shore sediment 
transport which seem to be an order of magnitude higher than calculated changes of long-shore sediment transport based on wave height changes.

\section{CONSEQUENCES FOR COASTAL FLOOD AND EROSION PROTECTION}

\section{Policies}

In general, five policies / strategies of coastal flood protection and erosion protection are being applied in coastal flood defense (Fig. 12), where the term limited intervention means to influence the oceanographic and/or hydrodynamic conditions with structures with the aim to limit their effects on the coast. These policies / strategies are mainly based on century long experiences in coastal engineering. A similar division in strategies has been suggested by IPCC (1990) based on first analyses of possible sea level rise and consequences for the coasts. The possible three adaptation strategies to accelerated sea level rise are i) retreat, ii) accommodation and iii) protection. At present (Hofstede et al, 2009) nearly all strategies are being applied by the responsible authorities in German coastal areas. The selection of an actual strategy is mainly a political decision which has to take into account several technical and especially non-technical (societal) conditions.

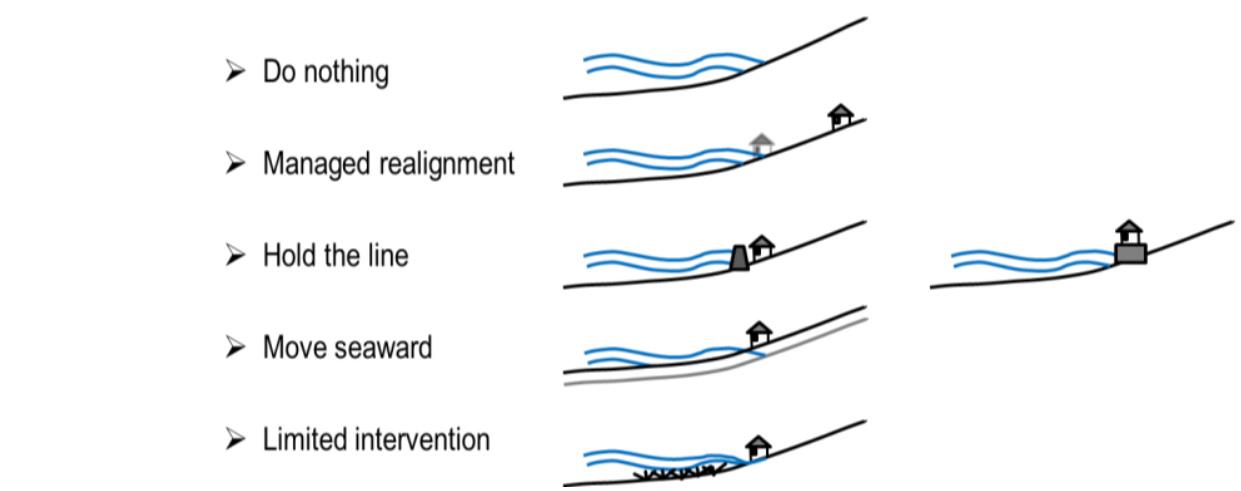

Figure 12. Coastal protection policies modified after IPCC (1990).

The described changes of loads of coastal flood protection measures and the changes of the local sediment transport as well as possible morphological development of coasts have a wide variety of consequences for the protection against flooding and for the protection of sandy coasts. Examples are:

1. the efficiency of actual coastal and flood protection measures and the future practical applicability of established measures and constructions,

2. the functional and constructional design of measures and constructions for the protection of sandy coasts,

3. the future safety of protected areas and changed (increased) risks in coastal areas,

4. the necessity of development of adaptation strategies, measures and adapted constructions

At present, especially the first point is under detailed investigation for dykes and flood protection dunes and adaptation measures are discussed.

Adaptation measures for selected flood defense constructions - possibilities and limitations

Possible adaptation measures can be derived from the general protection policies for coasts. Fig. 13 shows general possibilities for the adaptation of flood protection dunes to increased sea levels. Fig. 14 shows the respective possibilities for the adaptation of dikes. 

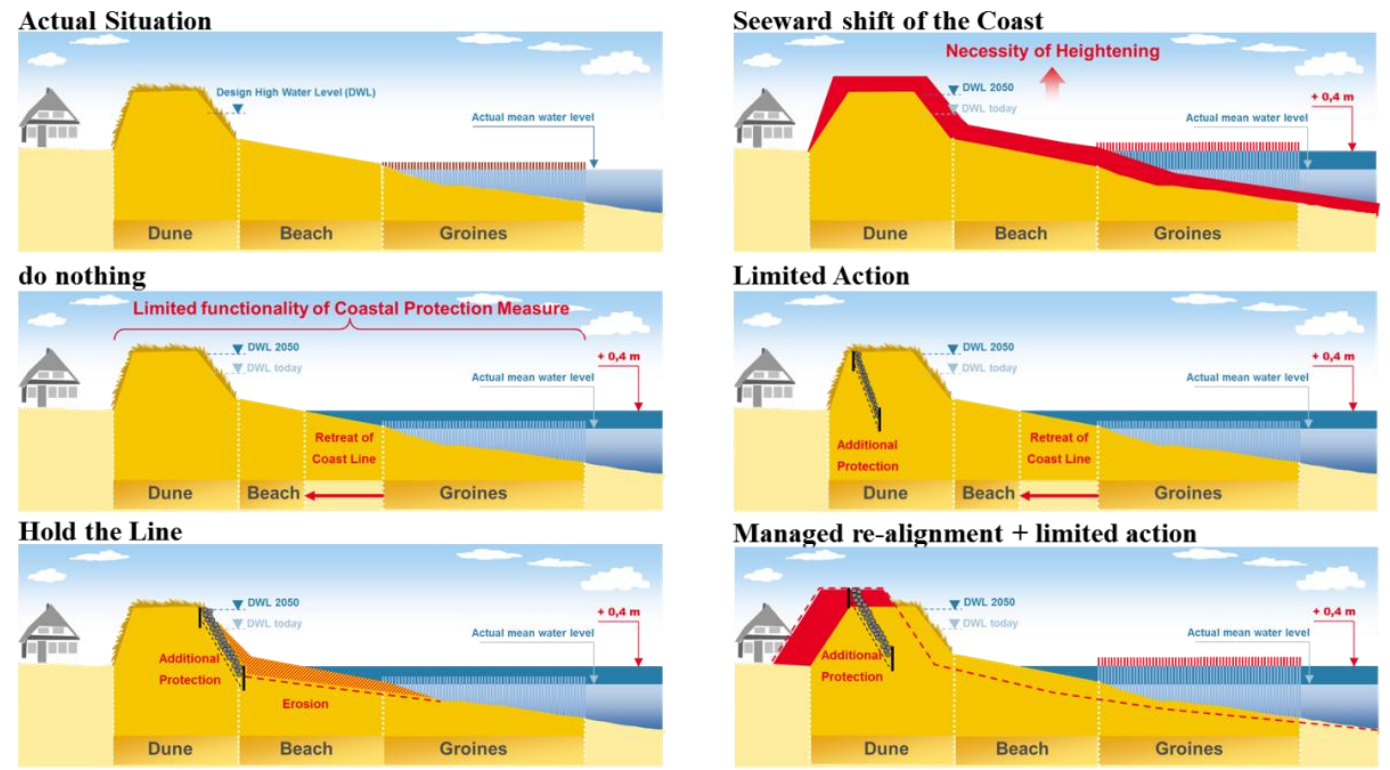

Figure 13. Adaptation of flood protection dune to effects of climate change.

In both cases, the do nothing option will end in a limited functionality of the flood protection measure. The probability of failure will increase with increasing water levels and, consequently, the risks in the protected areas will also increase. This may be acceptable up to a certain extent (period) for some coastal areas, but, finally the do nothing option will necessarily cause a retreat of continuous human action in the protected hinterland.
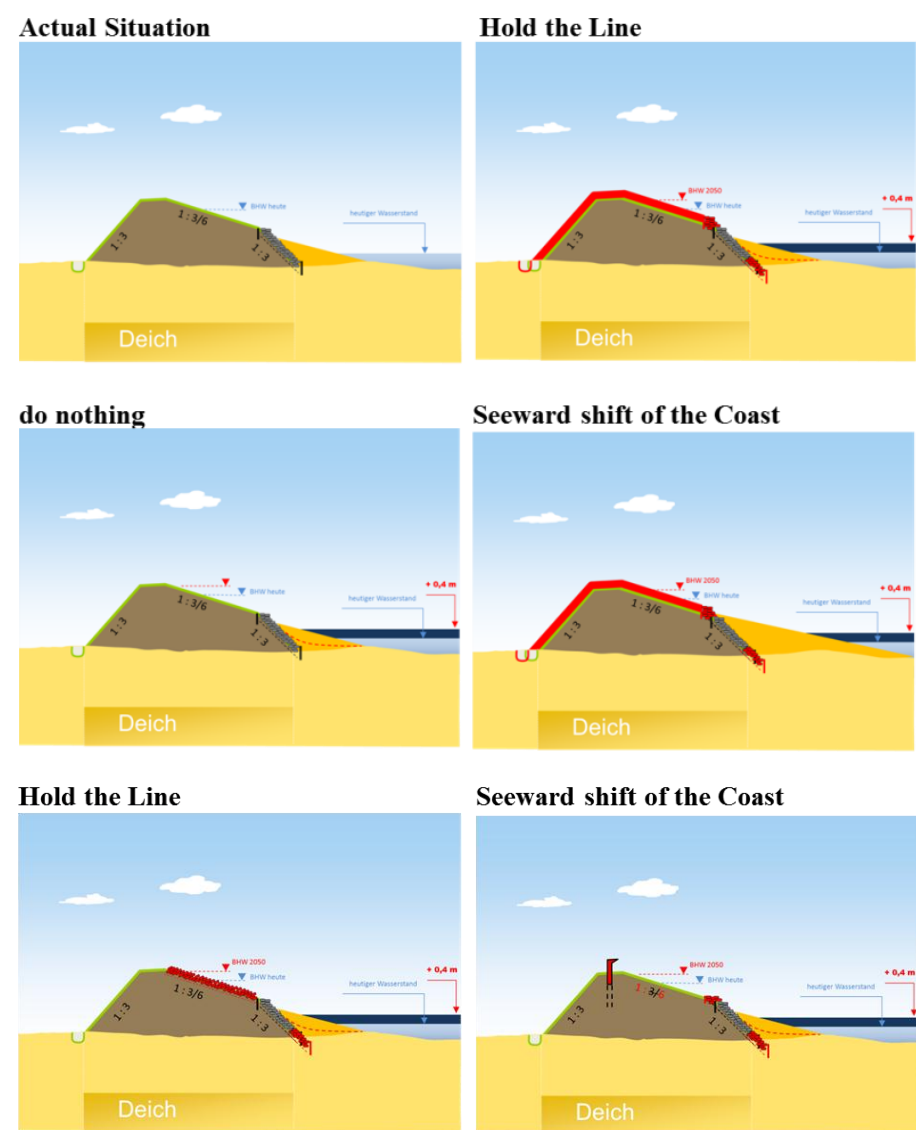

Seeward shift of the Coast

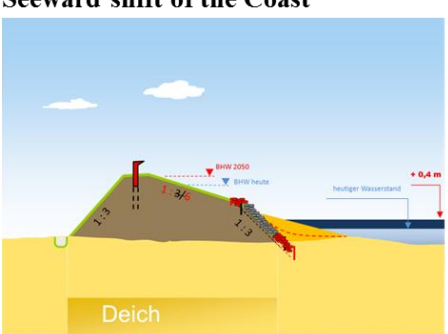

Figure 14. Adaptation of dikes to effects of climate change.
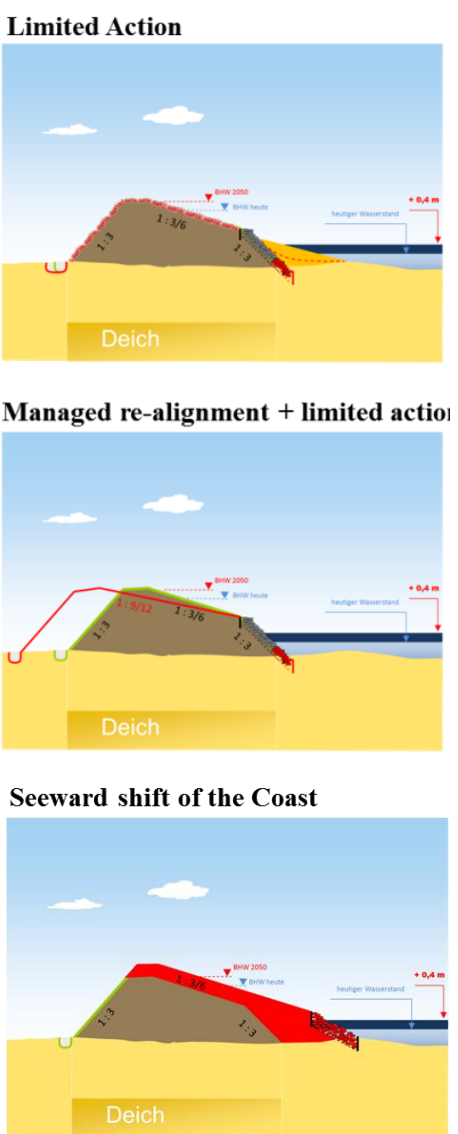
All solutions which are using hard constructions to defend the coast against sea level rise (hold the line option) show a significant change in the foreshore area, i.e. the foreland or coastal floodplain of the construction. In many cases the (sandy) beaches or the salt marshes will be eroding and an hard and rocky coast will be the result of such a protection.

A seaward shift of the coast seems to be the most appropriate solution. The whole coastal stretch from the dune/dike up to the depth of closure has to be heightened using material which is comparable to the natural material (i.e. gravel, sand, clay). If the increase of the level of the land and the sea level increase have the same value, no critical changes for the loads of the flood protection construction have to be assumed. Unfortunately, a huge amount of material is necessary with corresponding high costs to protect a coast in such a way. In addition, environmental problems may occur from the dredging of the material.

For both solutions also an option including additional research works for a better understanding of the failure mechanisms of flood protection measures and for a more reliable design must be taken into consideration. The actual design approaches, criteria and formulations for dunes and dikes are giving a wide variety of the respective results and must therefore be carefully analyzed in future research works.

The limited action option in combination with a managed part-re-alignment of the land use shows the most promising results. As the result, both, the use of the protected hinterland and also the use of the beach are more or less ensured. All adaptation methods to sea level rise have their limitations if the sea level is increasing too fast or if the total amount of the increase of the sea level is too high. From the technical point of view, adaptation to sea level rise of $0.5 \mathrm{~m}$ to $1.0 \mathrm{~m}$ should not be too problematic in many areas of the world if the costs for such protection measures could be financed. This is directly linked to socio-economic effects of coastal protection.

If moderate values of sea level rise $(0.5 \mathrm{~m}$ to $1.0 \mathrm{~m})$ are exceeded significantly, most coastal areas would change their morphological appearance considerably. Then, two options: i) giving up and realigment in higher areas of the hinterland or ii) hold the line would be the only option. If the coastal areas must be protected, the then necessary hard constructions would aggravate the process of morphological changes.

\section{CONCLUSIONS}

The following conclusions are drawn from the research:

1. Climate Change will have direct and indirect effects on Coastal Areas

- water levels will increase

- $\quad$ wave heights may increase in some areas

- $\quad$ wave directions will change

- frequency and intensity of storms will increase at least in some areas, which might also cause more intensive wave conditions

This will result in:

2. Higher loads on the coast and on coastal structures

- retreat of the coast

- changed long-shore sediment transport

3. without adaptation

- $\quad$ increase in probability of failure

- $\quad$ increase of flooded area

- $\quad$ increase of water level in flooded area

4. with adaptation

higher risks in coastal areas

- $\quad$ higher costs for coastal protection

Adaptation strategies for coastal protection must be developed, where, limitations caused by technical, aesthetical or socio-economic aspects have to be taken into account.

Further research on design approaches and design input data is needed in order to reduce the uncertainties. 


\section{ACKNOWLEDGMENTS}

The paper is based on investigations carried out in the research project RADOST. RADOST is supported by the German Federal Ministry for Education and Research (BMBF). The authors thank BMBF for the financial and logistic support and all project partners for the excellent co-operation. Altimetry data were provided by the NOAA Laboratory for Satellite Altimetry.

\section{REFERENCES}

Dreier, N., Schlamkow, C. , Fröhle, P. \& Salecker, D., Future wave conditions at the German Baltic Sea Coast on the basis of wind-wave-correlations and regional climate change scenarios, Proc. COPEDEC 2012, 20-24 February 2012, Chennai

Fröhle, P., Sea Level Rise and Coastal Protection - Adaptation Strategies for Sandy Coasts, In: Nova Acta Leopoldina N.F., Band 112, Nr. 384, Continents under Climate Change Conference on the Occasion of the 200th Anniversary of the Humboldt-University zu Berlin : 21 - 23 April 2010 / Endlicher, Wilfried; Gerstengarbe, Friedrich-Wilhelm (Eds.). Band 112, Nr. 384. , 2010.

Fröhle, P., Schlamkow, C., Dreier, N. \& Sommermeier, K., Climate Change and Coastal Protection: Adaptation Strategies for the German Baltic Sea Coast, In: Schernewski, G., Hofstede, J. \& Neumann, T. (eds.): Global Change and Baltic Coastal Zones, Chapter 7, Coastal Research Library 1, Springer 2011

Hofstede, J. L. A.: Entwicklung des Meeresspiegels und der Sturmfluten: Ist der anthropogene Klimawandel bereits sichtbar? Coastline Reports 9 (2007), S. 139 - 148

Hofstede, J. et al.: Küstenschutzstrategien, Bericht der EAK-Arbeitsgruppe "KÜSTENSCHUTZSTRATEGIEN". Die Küste, Heft 76, Heide, 2009

IPCC: Strategies for Adaptation to Sea Level Rise, Report of the Coastal Management Sub-group, http://www.ipcc.ch/, November 1990

IPCC: Fourth Assessment Report (AR4), http://www.ipcc.ch/, 2007

IPCC (2007) Climate Change 2007: The Physical Science Basis - Summary for Policymakers. Contribution of Working Group I to the Fourth Assessment Report of the Intergovernmental Panel on Climate Change. http://www.ipcc.ch. Accessed 13 March 2007

Meinke, I., Gerstner, E.-M. 2009: Digitaler Norddeutscher Klimaatlas informiert über möglichen künftigen Klimawandel. DMG Mitteilungen 3-2009, 17

Mori, N., T. Yasuda, H. Mase, R. Iwashima (2009) T. H. Tom and Y.Oku, Prediction of global sea surface wind and wave climate change based on MRI-JMA GCM, Proceedings of 33rd IAHR Congress, 2009

Rahmstorff, S.; Schellnhuber, H.-J.: Der Klimawandel. Diagnose, Prognose, Therapie, Verlag C.H. Beck, 2007

Schlamkow, C., Dreier, N., Fröhle, P. \& Salecker, D. 2012. Future Extreme Waves at the German Baltic Sea Coast derived from Regional Climate Model Runs. Proc. ICCE 2012, Santander (http://journals.tdl.org/ICCE)

Vermeer, M. and Rahmstorf S.: Global sea level linked to global temperature. PNAS Early Edition www.pnas.org/cgi/doi/10.1073/pnas.0907765106

von Storch, $\mathrm{H}$. et al.: The BACC Strategy, International Conference Climate Change: The environmental and socio-economic response in the southern Baltic region, 25-28 May 2009 in Szczecin, Poland

WBGU, Wissenschaftlicher Beirat der Bundesregierung Globale Umweltveränderungen: Kassensturz für den Weltklimavertrag - Der Budgetansatz, Sondergutachten, Berlin 2009 http://www.wbgu.de/fileadmin/templates/dateien/veroeffentlichungen/sondergutachten/sn2009/wb gu_sn2009.pdf

Witte, J.O., Kohlhase, S., Fröhle, P. \& Radomski, J.: Strategien und Optionen der Küstenschutzplanung Sylt, in: Daschkeit \& Schottes: Klimafolgen für Mensch und Küste am Beispiel der Nordseeinsel Sylt, Springer Verlag, Berlin Heidelberg, 2002 